\title{
0 retorno aos corantes naturais como forma de preservar o meio ambiente e sua importância histórica e cultural
}

Cristiane Rodrigues Neves possui Curso de moda e design: "Art and Design-Fashion and Textile" BTEC (Business Technology and Education)- South Thames College, Londres (2000). Licenciatura Plena em História- Centro Universitário Estácio de Sá (2018). Atualmente é mentora do curso online "Fashion as Design" do MoMA - NY. É membro do grupo "Fashion and Sustainability: Understanding Luxury Fashion in a Changing World; assim como, integrante do Circular Economy Club. Cursos complementares: "Building a Fashion Collection"Central Saint Martins; "How to build a sustainable fashion business- Ethical Fashion Forum; "Fashion and Sustainability- London College of Fashion; Business Future: Sustainable Business Through Green HR- RMIT.

$<$ rodriguesnevescristiane@gmail.com>

ORCID: 0000-0001-9092-2399
Resumo A moda está presente no nosso dia a dia e por meio de nossas roupas nos comunicamos de forma não verbal. Nesse sentido, a cor é parte importante. Contudo, a indústria de tingimento têxtil causa diversos problemas ao meio ambiente. Diante disso, uma possível alternativa é a utilização de corantes naturais. Este trabalho teve como objetivo destacar os corantes naturais como alternativa ecológica para a indústria da moda, além de sua importância cultural e histórica. Para isso, foi realizada uma busca na literatura que contemplou artigos e livros sobre os corantes naturais tanto da área do Design como de áreas afins. A literatura apontou que é possível utilizar antigas técnicas de tingimento, sendo muitas ecologicamente corretas. 0 retorno às velhas práticas pode contribuir tanto para a geração de emprego como para valorização dos saberes e da cultura de diferentes povos.

Palavras chave Meio ambiente, Corantes naturais, Design, Cultura. 


\section{The return of natural dyes as a way of preserving the environment and its historic and cultural importance}

Anne Velloso Sarmento Gomes é Mestranda em Design pela Universidade do Estado de Minas Gerais (UEMG), possui graduação em Química Licenciatura pela Universidade Federal de Minas Gerais (UFMG) (2018) e graduação com Láurea Acadêmica em Design de Moda pela Universidade FUMEC (2011). Atua no mestrado na área de design e materiais. <annevelloso.design@gmail.com> ORCID: 0000-0003-0731-3459
Abstract Fashion is present in our daily lives through our clothes and we communicate non-verbally. Thus, color plays an important role. However, the textile dyeing industry causes several damages to the environment. Therefore, natural dyeing is seen as a possible alternative. This study aimed to highlight the natural dyes as an ecological alternative to the fashion industry along with their cultural and historical importance. For this, a research was carried out in the literature that included articles and books about natural dyes, in the Design area, and also in related areas. The literature pointed out that it is possible to use old dyeing techniques, many of which are sustainable. The return to old practices can contribute both to create jobs, as well as to give value to people's knowledge and their culture.

Keywords Environment, Natural dyes, Design, Culture.

La vuelta a los tintes naturales como forma de preservar el medio ambiente y su importancia histórica y cultural

Resumen La moda está presente en nuestro día a día, a través de nuestra ropa nos comunicamos de forma no verbal. En este sentido, el color es una parte importante, sin embargo la industria del teñido de textiles causa varios problemas al medio ambiente. Por tanto, una posible alternativa es el uso de tintes naturales. Este trabajo tuvo como objetivo resaltar los tintes naturales como alternativa ecológica para la industria de la moda, además de su importancia cultural e histórica. Para ello, se realizó una búsqueda en la literatura que incluyó artículos y libros sobre tintes naturales, tanto en el área de Diseño, como en áreas afines. La literatura señaló que es posible utilizar técnicas de teñido antiguas, muchas de las cuales son respetuosas con el medio ambiente. La vuelta a las viejas prácticas puede contribuir tanto a la generación de empleo, como a la valorización del conocimiento y la cultura de diferentes pueblos.

Palabras clave Medio ambiente, Tintes naturales, Diseño, Cultura. 


\section{Introdução}

A moda está no cotidiano das pessoas. Sem ao menos perceber, todos os dias precisamos fazer escolhas do que vestir. É como uma pele que escolhemos. Em um nível subjetivo, representa como nos sentimos sobre nós mesmos e o que queremos passar ao mundo sobre quem somos em termos sociais. A roupa conta nossa história, cultura e costumes (DITTY, 2015). Segundo Saravanan e Nithyaprakash (2015), a moda não é apenas uma imagem que se cria para representar um papel na sociedade. A aparência do indivíduo transmite sinais não verbais de comunicação, como pistas sobre sua classe social, valores e estilo de vida. A moda pode ter relação com crenças e atitudes de membros de determinados grupos sociais. Os adornos revelam as experiências emocionais do indivíduo e relacionam-se com valores do grupo que está inserido. Para Kant (2012) a cor é um fator importante. Se tratando de tecido, a cor é o principal atrativo. Não importa quão excelente é o material, a cor será sempre o principal fator de atração. Se não é agradável, está fadado ao fracasso comercial.

Tempos atrás as roupas eram feitas sob encomenda por alfaiates e vendidas para a aristocracia em eventos privados. A moda como design de luxo das passarelas aconteceria mais tarde nos grandes centros urbanos, ainda produzida em uma escala relativamente pequena. Em meados dos anos 2000, a moda tornou-se um enorme negócio global com produção em vários países em desenvolvimento que ofereciam salários mais baixos e menos proteção aos trabalhadores e ao meio ambiente. Em uma rápida ascensão, a indústria da moda é um dos setores mais influentes, tanto em poder econômico quanto em moldar comportamento, identidade e cultura. Este setor emprega mais de 60 milhões de pessoas. A produção artesanal é o segundo campo de trabalho que mais gera emprego nos países em desenvolvimento, sendo que apenas a Índia conta com 34 milhões de artesãos, dentre eles, tecelões, tintureiros e agricultores envolvidos na produção e venda de roupas (DITTY, 2015). Porém, neste momento o mundo se encontra, em parte, paralisado pela crise do COVID-19. Em meio a este problema de saúde pública global, surge uma rara oportunidade para que a indústria da moda seja repensada de forma mais sustentável, principalmente, para os já consolidados negócios de moda que controlam uma grande parte da cadeia de valor do setor, assim como pode ser o momento perfeito para mentes inovadoras com ideias que possam melhorar o atual status quo ${ }^{1}$ (MAGNUSDOTTIR, 2020).

Schulte et al. (2013) e Viana et al. (2016) afirmam que a preocupação com o meio ambiente é algo que vem crescendo como fator importante na escolha de um produto por parte de seus consumidores e usuários. Nesse contexto, o retorno às antigas práticas da produção têxtil é apontado como alternativa às que causam danos ao meio ambiente. Nesse sentido, os corantes naturais estão sendo vistos como uma alternativa aos corantes sintéticos (ISENMANN, 2014; KADOLPH, 2008). 
Dessa forma, temos como principal objetivo destacar não só os corantes naturais como uma alternativa ecológica na área de moda, como também apontar algumas de suas múltiplas histórias e importância cultural, uma vez que o uso de diversos agentes colorantes faz parte da história de diferentes povos. Outro ponto importante é que a utilização de corantes naturais, por estar atrelada ao tingimento artesanal, pode contribuir para a inclusão social e a geração de emprego e renda.

\section{Metodologia}

A metodologia utilizada neste trabalho consistiu em uma busca na literatura, do tipo revisão narrativa, tanto contemplando artigos e livros em periódicos pertencentes tanto à área do Design como em áreas afins que abordaram o tema de corantes naturais e sua relação histórica e cultural com a moda e o meio ambiente.

\section{História e cultura}

Anteriormente à descoberta dos corantes sintéticos os tecidos eram tingidos com corantes oriundos da natureza, de origem vegetal, animal ou mineral (ISENMANN, 2014; PEZZOLO, 2013). Segundo Pezzolo (2013), pertence à China de 2600 a. C. os primeiros registros da utilização dos corantes naturais. Outro fator importante da história da tinturaria é que até o rompimento das fronteiras com as grandes navegações a utilização de corantes e mordentes (agentes responsáveis pela fixação da cor) estava ligada à sua disponibilidade regional (ISENMANN, 2014; PEZZOLO, 2013).

A história dos corantes pode ser contada não como sendo única, mas como múltipla que varia de acordo com a localização geográfica, bem como a cultura e a sociedade que norteiam seus principais atores (os tintureiros). Em diferentes culturas, as práticas tradicionais de tingimento revelam um saber apurado dos povos locais sobre os corantes e demais substâncias utilizadas no tingimento. Segundo Cunningham et al. (2011), o conhecimento da utilização de determinadas plantas para a fixação das cores nas fibras de algodão tem raízes históricas. Devido à grande variedade de cores dos corantes, as receitas eram protegidas e raramente registradas. Esses saberes são passados por meio da história oral e revelam muito sobre a química do tingimento e a cultura desses povos (KADOLPH, 2008).

Uma das cores que teve grande destaque na história dos corantes foi a púrpura, oriunda do corante púrpura de Tiro, ou púrpura dos antigos. Segundo Araújo (2007), ele foi o corante mais caro da Antiguidade. Era símbolo de distinção, o que levou o imperador Nero de Roma a criar uma lei que punia com pena de morte quem ousasse usar roupa tingida com púrpura (ARAÚJO, 2007; PEZZOLO, 2013). Os fenícios comercializavam o corante que era extraído do molusco do gênero Murex, sendo que cada espécie tinha uma variedade distinta de púrpura (ARAÚJO, 2007). 
As técnicas de tingimento foram mais desenvolvidas na Ásia, principalmente na Índia, contudo, os povos nativos americanos contavam com uma infinidade de plantas tintureiras (PEZZOLO, 2013). As civilizações mesoamericanas como Olmecas, Maias, Astecas e Teotihuacán faziam uso de substâncias naturais para tingir objetos durante o período pré-hispânico (2000 a.c-1524). As aplicações de corantes podem ser notadas em peças artísticas como murais, máscaras e fragmentos de tecidos (CHAN-BACAB et al., 2015).

Foi durante a época das Grandes Navegações que os portugueses e os espanhóis levaram os corantes da América para o velho continente, o que acabou por tirar o monopólio comercial dos italianos, que até então importavam os corantes e o alúmen (mordente, fixador) dos países do mediterrâneo para comercializá-los na Europa (PEZZOLO, 2013). Os colonizadores se interessaram pelos corantes dos nativos, visto que traziam grandes lucros para a metrópole, ficando atrás apenas dos metais preciosos (GUIROLA, 2010). Os corantes naturais, bem como outros produtos, eram mantidos em segredo quanto ao local da fonte, dado o seu alto valor comercial (ARAÚJO, 2007).

O território da Guatemala foi uma das joias da coroa espanhola pois contava com solo fértil. Nele podiam ser encontrados diversos produtos como: cedro, mogno, pau-brasil, ervas medicinais, urucum (também conhecido por anato e achiote), cacau, baunilha e o índigo. Esse último fora de grande interesse para os colonizadores, visto que era o produto de maior importância econômica na Europa desde o início do século XVI (BRATES et al., 2005; PEZZOLO, 2013).

Além de sua importância econômica, o corante azul índigo é considerado pelos historiadores como o corante mais antigo, uma vez que os egípcios, chineses e fenícios já o conheciam desde 600 a.C. Ele é extraído das folhas de várias espécies da anileira (Indigofera). Dentre essas espécies a Indigofera tinctoria, nativa da Índia (daí o nome do latim indicum, de Índia), é considerada a mais valorizada para a extração do corante. Durante o período de colonização, no século XIX, essa espécie rendeu grandes lucros para a coroa britânica (ARAÚJO, 2007; BRATES et al., 2005; PEZZOLO, 2013).

Além da púrpura e do índigo, os tons de vermelho tiveram destaque entre os corantes naturais. Várias plantas eram utilizadas pelos povos indígenas na América, dentre elas, o urucum, que fornece uma cor vermelha alaranjada que era usado tanto para o tingimento quanto na culinária (GUIROLA, 2010). O pau-brasil fornecia outro tom de vermelho. A Europa já utilizava o pau-brasil como corante desde a Idade Média, sendo seu maior produtor o Sri-Lanka, antiga Ilha do Ceilão, que comercializava com o Egito e esse último com a Europa (ARAÚJO, 2007). Outra fonte de corante vermelho conhecida dos europeus era da planta ruiva dos tintureiros (Rubia tinctorum). o tecido tingido com essa planta é de um vermelho muito brilhante, conhecido como vermelho turco (ARAÚJO, 2007; ISENMANN, 2014). Os colonizadores espanhóis notaram o grande valor econômico dessas espécies. Em um processo de troca, vários produtos como tecidos e outras técnicas de tingimento chegaram da Europa, sendo que algumas foram mescladas e outras substituídas pelos locais (GUIROLA, 2010). 
Além de plantas tintoriais, os tons de vermelho eram extraídos de fontes animais. Os nativos mexicanos e os povos andinos do Peru, faziam uso do corante cochonilha extraído do besouro de mesmo nome muito antes da chegada dos colonizadores. Esses ficaram impressionados com a cor intensa e brilhante do vermelho extraído desse inseto (PEZZOLO, 2013). 0 corante cochonilha é obtido de duas espécies de insetos, a Nopalea coccinilifera e a Dactylopius, que se desenvolvem em um cacto originado do México (ARAÚJO, 2007). Até então, os espanhóis conheciam o corante vermelho obtido de outro inseto, o Quermes ou Grã. A substância era extraída das fêmeas grávidas do pulgão Kermes illici - inseto que vive sobre as árvores de carvalho. Os povos babilônios já utilizavam o Quermes como corante (ARAÚJO, 2007; ISENMANN, 2014; PEZZOLO, 2013).

Até 1856, quando William Perkin criou o primeiro corante sintético, a anilina (ou malveína), em Londres, a natureza era a fonte dos corantes para tecidos (KADOLPH, 2008). Embora os corantes sintéticos tenham sido aceitos por grande parte da sociedade britânica, havia um debate de prós e contras, usando como exemplo mulheres britânicas que voltavam de eventos sociais com seus corpos manchados de anilina proveniente dos seus vestidos, o que levou a grandes disputas entre os que apoiavam a novidade e os que preferiam os corantes naturais (CASSELMAN, 2009). Houve um fato observado também pelo escritor Charles Dickens, que escreveu no periódico All Year Round, de 1859, sobre as mãos manchadas de corante que acenavam das carruagens (FORSTER; CHRISTIE, 2013). A partir de 1910, a grande maioria dos tecidos comercializados na Europa e nos Estados Unidos era tingida com corantes sintéticos. Por volta de 1930, muitos tintureiros de países em desenvolvimento já tinham abandonado os corantes naturais pelos sintéticos (KADOLPH, 2008).

A utilização dos corantes sintéticos na indústria têxtil é justificada pelos seguintes fatores: maior fixação, maior diversidade de cores e tonalidades, maior grau de pureza, reprodutibilidade técnica, flexibilidade de localização (podem ser produzidos em qualquer local, não dependendo do clima, solo e técnicas adequadas de cultivo) e menor custo de produção (ISENMANN, 2014; SHAHID; ISLAM; MOHAMMAD, 2013; ZANONI; YAMANAKA, 2016). Contudo, segundo Casselman (2009), a baixa fixação relacionada aos corantes naturais é algo questionável, pois em alguma medida, todos os tecidos se desvanecem. Em três décadas de pesquisa em instituições de vários países, a referida pesquisadora analisou diversas coleções e foi constatado o desbotamento em tecidos tingidos tanto com corantes naturais quanto com corantes sintéticos. Logo, concluiu que o modo como a roupa foi usada e seu cuidado durante o tempo de uso são fatores que podem influenciar no declínio da cor. 
Além dos corantes para tingimento de tecido, entram no processo outras substâncias. Dentre elas, podemos destacar as responsáveis pela fixação da cor, que são conhecidas como mordentes (PEZZOLO, 2013; SHAHID; ISLAM; MOHAMMAD, 2013). Mordente, palavra originada do francês antigo (mordre - morder), são substâncias que formam ligações químicas estáveis necessárias para fixar a cor nas fibras do tecido (CUNNINGHAM et al., 2011; ZANONI; YAMANAKA, 2016). Além de terem papel fundamental na fixação de corantes naturais, que não são do tipo corantes mordentes (aqueles que não necessitam de uma substância para se fixarem), os mordentes podem gerar alteração na cor de alguns corantes (clarear, escurecer ou mudar completamente a cor de um corante) (ISENMANN, 2014; SHAHID; ISLAM; MOHAMMAD, 2013). A cor vermelha, por exemplo, era símbolo de status em várias culturas por ser a mais difícil de conseguir. O mordente exercia papel decisivo para a obtenção de um vermelho vivo e brilhante (CUNNINGHAM et al., 2011).

O mordente pode ser aplicado antes, durante ou depois do processo de tingimento. Antes da invenção do mordente sintético, os disponíveis eram de origem vegetal, mineral e animal. Há relatos da utilização de urina humana como mordente pelos gregos, romanos e os povos astecas. Os europeus, na Idade Média utilizavam o alúmen, cinzas de madeira, tártaro, ferrugem, vinagre e azeite de oliva (ARAÚJO, 2007; CUNNINGHAM et al., 2011; PEZZOLO, 2013). Na Índia, os povos hindus usavam como mordente uma mistura de leite e raiz de ruiva indiana (Rubia tintorium L.) (ARAÚJO, 2007).

De acordo com Kadolph (2008), os corantes naturais são substantivos ou aditivos. Os substantivos são conhecidos por corantes mordentes. Enquanto que os corantes naturais aditivos precisam da adição de um "assistente" químico, tal como um sal metálico. $O$ que acontece é a formação de ligações químicas entre os corantes e a fibra por meio do mordente. Os sais inorgânicos utilizados como mordentes mais comuns são: alúmen (sulfato duplo de alumínio e potássio), cobre (sulfato de cobre), ferro (sulfato ferroso), dicromato de potássio e o cloreto estanoso. Muitos desses agentes são tóxicos e prejudiciais à saúde e ao meio ambiente, contudo, os mordentes de alumínio são os mais usados por serem os mais seguros nos processos de tingimento (CHAN-BACAB, 2015; SHAHID; ISLAM; MOHAMMAD, 2013).

Dentre os sais mordentes o alúmen é tido como um mordente muito antigo. Há registros de sua utilização entre os povos da Mesopotâmia, da Grécia Antiga e pelos nativos americanos (ARAÚJO, 2007). O Alúmen foi um produto que gerou grande riqueza na época do Renascimento italiano. Florença, Gênova e Veneza comercializavam o mineral que era extraído de jazidas (ARAÚJO, 2007; ISENMANN, 2014). Porém, muitos tintureiros da Indonésia, há séculos, já utilizavam o alúmen de origem vegetal. Há mais de 260 anos, Rumphius (1743) escreveu sobre o conhecimento que os povos asiáticos tinham sobre a planta "albume", mais tarde identificada como 
Symplocos, usada pelos produtores de tecidos daquela localidade. Os tintureiros do sul e sudeste da Ásia selecionavam plantas hiperacumuladoras de metais, que hoje são conhecidas como uma característica limitada a determinadas plantas (JANSEN et al. 2002). Isto chamou a atenção dos cientistas europeus para a hiperacumulação de alumínio (Al) em plantas pela primeira vez. $O$ ritual usado no processo de tingimento em que a substância mordente é extraída de plantas resulta em um tingimento inteiramente natural, sem agressão ao meio ambiente. Cunningham et al. (2011), apontam que os tintureiros da América do Sul também utilizavam o Symplocos. Ao contrário dos povos asiáticos que utilizavam as folhas como mordente, os povos nativos da América preferiam as cascas, por terem níveis mais concentrados de $\mathrm{Al}$.

Além das plantas hiperacumuladoras de $\mathrm{Al}$, outro mordente vegetal muito utilizado era o tanino (ácido tânico). Há relatos de sua utilização por vários povos antigos na Europa, na Ásia e pelos nativos americanos. Essa substância era encontrada na noz de galha (Querus infectoria), na Campeche (Hematoxilon capechianum), entre outros (ARAÚJO, 2007). Os taninos são encontrados em várias partes das plantas, desde as suas raízes até os galhos. Há mais relatos de sua utilização no tingimento da fibra de algodão por essa ser menos compatível com os corantes naturais (SHAHID; ISLAM; MOHAMMAD, 2013).

\section{Meio ambiente e sustentabilidade: uma preocupação global}

A primeira Conferência da Organização das Nações Unidas (ONU) sobre questões ambientais aconteceu em Estocolmo, Suécia, em junho de 1972. Em seu primeiro capítulo, o documento manifestou grande preocupação com as evidências crescentes de danos causados pelo homem em muitas regiões da Terra, tais como os altos níveis de poluição na água, no ar, e no solo, que afetam os seres vivos, além da destruição e esgotamento de recursos naturais. Esses problemas causam grandes e indesejáveis perturbações ao equilíbrio ecológico, além de afetar a saúde física, mental e social do homem (UNITED NATIONS CONFERENCE ON THE HUMAN ENVIRONMENT, 1972).

Vinte anos mais tarde, a cidade do Rio de Janeiro foi sede de um novo encontro de chefes de Estado: a Conferência das Nações Unidas sobre Meio Ambiente e Desenvolvimento, conhecida como Rio-92. No referido encontro foram discutidas as questões ambientais que culminaram no documento Agenda 21. Dentre os vários acordos firmados, o desenvolvimento sustentável deveria se tornar um item prioritário na agenda da comunidade internacional (UNITED NATIONS CONFERENCE ON ENVIRONMENT \& DEVELOPMENT, 1992).

Em 2012, o Brasil foi sede, novamente na cidade do Rio de Janeiro, da conferência que ficou conhecida como Rio+20, por ter marcado os vinte anos de realização da Rio-92. Esta reunião contribuiu para a definição da agenda do desenvolvimento sustentável para as próximas décadas (UNITED NATIONS CONFERENCE ON SUSTAINABLE DEVELOPMENT RIO+20, 2012). 
Por fim, em setembro de 2015, aconteceu em Nova York, na sede da Organização das Nações Unidas (ONU), um encontro de mais de 150 líderes mundiais para a adoção de uma nova agenda de desenvolvimento sustentável. $O$ encontro resultou em uma agenda contendo 17 Objetivos de Desenvolvimento Sustentável (ODS), que devem ser implementados por todos os países do mundo durante os próximos 15 anos, até 2030. Dentre os objetivos estão: garantir uma vida saudável e promover o bem-estar das pessoas; seguir padrões de produção e consumo de forma sustentável; utilizar ecossistemas terrestres de forma a promover a sustentabilidade (TRANSFORMING OUR WORLD: THE 2030 AGENDA FOR SUSTAINABLE DEVELOPMENT, 2015).

\section{0 meio ambiente e a indústria têxtil}

A indústria têxtil foi o setor que mais gerou riqueza no século XIX, sendo sinônimo de tecnologia e progresso. Porém, trouxe grandes problemas para o meio ambiente e para os trabalhadores que passavam longas horas em locais sem condições de segurança e por vezes, insalubres (TERINTE et al., 2014). Esta indústria é uma das que mais polui, estando atrás apenas do setor agrícola. Isto se dá porque ela utiliza mais de 8.000 substâncias nos processos de tingimento e impressão (KANT, 2012).

Os processos responsáveis por conferir cores a um tecido (beneficiamentos secundários) representam uma parte importante do processo de fabricação têxtil. Além deles, há processos que os antecedem (beneficiamentos primários) e que os sucedem (beneficiamentos terciários) (GOMES; COSTA; MOHALLEM, 2016; PEZZOLO, 2013). A sustentabilidade na produção têxtil é um assunto que deve nortear todos os processos. Isto significa que os insumos utilizados na produção das fibras, os processos de plantio e colheita, as escolhas no processamento de fibras desde sua extração a limpeza, a produção de fios, a maneira de tecer, os benefícios secundários (tingimento e estamparia) e terciários (agentes que melhoram as características físico-químicas dos tecidos), bem como os processos de uso e conservação dos artigos têxteis são todos aspectos importantes para uma produção sustentável, incluindo ainda o olhar para os resíduos gerados no final da vida desses artigos (PEZZOLO, 2013; SCHULTE et al., 2013 ; VIANA et al., 2016).

As águas residuais das indústrias têxteis, que são oriundas dos processos de beneficiamento, inclusive os que envolvem corantes, têm causado grande preocupação para as estações de tratamento. Um dos problemas mais sérios dos resíduos têxteis é a diminuição do oxigênio dissolvido (OD) nas águas, pois o OD é essencial para a vida marinha. Além disso, se esses resíduos são escoados nos rios, eles afetam a água potável a tornando imprópria para consumo. 0 solo também fica comprometido quando eles atingem os campos e obstruem os poros da terra, o que torna o solo endurecido dificultando a penetração das raízes, resultando em pouca produtividade 
(KANT, 2012). Outro problema é que nos resíduos existem diversas substâncias tóxicas, que podem ser absorvidas pela pele por contato direto ou evaporarem, causando desde reações alérgicas até danos aos bebês antes mesmo do nascimento (HANDAYANI; KRISTIJANTO; HUNGA, 2018; KANT, 2012).

A Organização Mundial da Saúde (OMS) baniu alguns corantes sintéticos, dado seu alto risco para a saúde, o que fez crescer ainda mais o interesse dos consumidores por produtos orgânicos e ecologicamente corretos. Esse movimento vem ocorrendo em maior proporção nos países industrializados. Uma empresa não pode alegar vender um produto ecologicamente correto se o processo de tingimento usado polui as águas. Assim, esse movimento por produtos mais ecológicos está trazendo um grande desafio para a indústria do vestuário (BRATES et al., 2005). Empresas do setor têxtil, em 2010, uniram-se em torno de um acordo pela sustentabilidade com o objetivo de diminuir os impactos sociais e ambientais causados pelas indústrias de roupas e calçados em várias partes do mundo (TERINTE et al., 2014).

Desse modo, o retorno às antigas práticas na produção têxtil é apontado como alternativa àquelas que causam problemas ao meio ambiente. Nesse sentido, os corantes naturais são vistos como uma alternativa aos corantes sintéticos, pois os primeiros são extraídos de fontes renováveis enquanto os sintéticos são derivados de alcatrão e de petróleo, sendo assim, não renováveis (ISENMANN, 2014; KADOLPH, 2008).

\section{Corantes naturais: matéria prima e sustentabilidade}

O problema da degradação do meio ambiente tem levado governos de vários países a incentivarem práticas mais sustentáveis na área têxtil. Existem, por exemplo, incentivos à produção de corantes naturais na América Latina e na Ásia. Várias administrações locais têm criado programas de incentivo à pesquisa e à extração de corantes naturais. Muitas localidades contam inclusive com sindicatos de tintureiros. Tais atitudes vão ao encontro do pensamento de Nurse (2007), que afirma que a sustentabilidade social engloba não apenas valores sociais, políticos e comunitários, mas também ética, educação e atitudes de trabalho que possam suprir as necessidades básicas de uma sociedade.

Embora os corantes naturais sejam considerados ecológicos (HANDAYANI; KRISTIJANTO; HUNGA, 2018), sua extração tanto pode ser uma prática nociva ao meio ambiente por levar à extinção de espécies, como pode não ser prejudicial, tendo caráter sustentável (VIANA et al., 2016). Segundo a Organização Não-Governamental Yayasan Pecinta Budaya Bebali (YPBB) (2008 apud CUNNINGHAM et al., 2011), na ilha de Flores, Indonésia, algumas florestas de Symplocos são afetadas pela colheita destrutiva para a comercialização entre ilhas. Um dos problemas que contribuiu para a diminuição dessa espécie é a utilização não somente das folhas, mas também das cascas. A solução que foi adotada, junto à comunidade, para a preservação dessas espécies foi a criação de um plano de gestão de recursos em que 
são utilizadas apenas as folhas secas que caem das árvores. Foi uma grande iniciativa que contribuiu para a preservação de uma das últimas florestas remanescentes em Flores. $O$ fato desta floresta ser rica em outras plantas que apresentam interesse comercial tem fornecido incentivo para o manejo florestal comunitário. Esta iniciativa está progredindo bem, com apoio político e administrativo sob a política de descentralização florestal da Indonésia.

$\mathrm{Na}$ cidade de El Quiché, Guatemala, vários projetos foram criados para o desenvolvimento ambiental e econômico de diversas comunidades indígenas. Técnicas de cultivos de plantas e elaboração de ferramentas para o tingimento têxtil foram combinadas com fazeres ancestrais. Cerca de 50 agricultores estão cultivando o índigo para fins comerciais. Em El Salvador, o Conselho Nacional de Cultura e Arte (CONCULTURA) tem feito parceria com várias organizações internacionais e já exportam o anil (índigo) para a Alemanha, Suíça, França, Turquia e Japão. Além disso, o país tem planos para incluir a Inglaterra e os Estados Unidos, dentre outros países, para exportação. É um trabalho que conta com a comunidade local, pois são os mais velhos que estão ensinando os mais novos como dar o "ponto" ao índigo (BRATES et al., 2005). Nota-se a importância da herança imaterial do "como fazer", passado de geração para geração, além do reconhecimento e preservação da cultura e tradição desses povos. O projeto corrobora a importância desse patrimônio. Segundo a UNESCO (Organização das Nações Unidas para a Educação, Ciência e Cultura), patrimônio cultural imaterial é entendido como as práticas, representações e habilidades associadas a determinados povos, como o artesanato tradicional, suas expressões e tradições orais, bem como o conhecimento e práticas referente à natureza e ao universo. Tais saberes são transmitidos entre gerações, o que proporciona senso de identidade e continuidade. 0 respeito para com a diversidade humana e sua herança imaterial é parte do desenvolvimento sustentável (CONVENTION FOR THE SAFEGUARDING OF INTANGIBLE CULTURAL HERITAGE, 2003).

$\mathrm{Na}$ Indonésia, as plantas da espécie Symplocos (mordente vegetal) são comercializadas entre as várias ilhas do país e, também, para os turistas estrangeiros interessados em tinturas artesanais e ecológicas. Os nativos estão juntando tradição e modernidade. Os 50 membros de uma cooperativa da Ilha de Flores mantêm suas tradições de dança e música enquanto vendem seus tecidos aos turistas (CUNNINGHAM et al., 2011).

A Índia conta com programas de pesquisa focados em produtos tingidos com corantes naturais, bem como investe na melhoria da resistência das cores da mesma maneira que incentiva a descoberta de novos corantes. O México possui fazendas para criadouros de besouros cochonilha e a República Dominicana tem cultivado plantas tintureiras para o uso comercial de corantes azuis, cinzas e pretos (KADOLPH, 2008).

As plantas tintureiras despertaram interesse de pesquisa na Escola de Artes, Ciências e Humanidades (EACH) da Universidade de São Paulo (USP). Foi realizado um estudo que consistiu em pesquisar na natureza corantes que pudessem ser utilizados em tecidos. O local escolhido foi a Flo- 
resta Amazônica por sua grande variedade de plantas e outros aditivos naturais que movimentam a economia e o mercado local (RODRIGUES, 2013). O estudo envolveu a utilização de corantes extraídos de cascas do tronco da mamorana, da andiroba, do cipó de verônica e do urucum, assim como da polpa do açaí e do jenipapo. Essa investigação consistiu tanto na análise das técnicas e condições empregadas no tingimento têxtil como na solidez à lavagem e à luz dos artigos tingidos. Verificou-se que por meio da utilização dos corantes naturais empregados é possível amenizar os impactos ambientais gerados no tingimento têxtil, uma vez que os corantes utilizados, por serem oriundos da natureza, possuem uma composição química menos agressiva ao meio ambiente. Além disso, os resultados mostraram corantes aptos a serem usados na indústria têxtil e que incentivos por parte dela podem contribuir para movimentar a economia dos locais de extração (RODRIGUES, 2013; RODRIGUES; ARAÚJO, 2013).

Em Muzambinho, Sul de Minas Gerais, foi criado em 2003 o projeto Amaria, idealizado pela designer e arquiteta nipo-brasileira Mayumi Ito. 0 projeto conta com uma equipe de artesãs, entre costureiras, tecelãs, bordadeiras e tintureiras. As peças criadas começam com o tingimento das fibras com corantes naturais extraído de plantas locais, principalmente, de sobras das colheitas de café (frutos, galhos e folhas) para a fabricação posterior do tecido nos teares manuais, corte e montagem das peças. É uma iniciativa que fomenta um relacionamento com a população rural ao valorizar a sabedoria tradicional, gerando emprego, renda e autoestima. O projeto obteve reconhecimento internacional ao promover um diálogo entre artistas brasileiros e designers japoneses. Ao reconhecer o valor do artesanato local, a designer e a comunidade desenvolveram um trabalho inovador de expressão global que trouxe orgulho para a população local (ARTESOL, 2020; ROCHA, 2018).

Nesse sentido, os referidos projetos vão ao encontro do pensamento de Nurse (2007), que observa a cultura como um dos pilares do desenvolvimento sustentável que deve estar relacionada com objetivos econômicos e sociais, bem como, com a identidade social dos grupos, seus signos e conhecimentos que moldam a vida naquele ambiente. A tradição, como patrimônio cultural, envolve as comunidades através de parcerias entre governos e sociedade civil para a gestão sustentável desse patrimônio, a fim de ensinar e transmitir os valores e conhecimentos locais. Desse modo, a proteção do patrimônio cultural e do conjunto dos bens intangíveis, conhecimentos e habilidades que definem coletivamente as comunidades podem ser considerados como uma contribuição para o bem-estar humano (ASTARA, 2014). 


\section{Considerações finais}

Desde a década de 70 tem crescido uma consciência sobre a importância da preservação do meio ambiente. Este estudo fez uma análise das possíveis práticas mais sustentáveis na indústria de moda, conhecida por ser um dos setores que mais polui o meio ambiente, tendo como destaque os processos usados no tingimento dos tecidos.

Atualmente, em diversos locais do mundo, a indústria da moda está em um momento de paralisação devido à crise do CoVID-19. Contudo, este é um momento oportuno para buscar em antigas práticas subsídios para um fazer da moda de forma mais sustentável. Neste estudo, observou-se que é possível recuperar velhas práticas e formas mais sustentáveis, ao mesmo tempo em que é possível gerar emprego e valorizar os saberes e valores culturais. As práticas típicas da Guatemala e o projeto Amaria da cidade de Muzambinho, Minas Gerais, são exemplos de como a herança imaterial e práticas ancestrais locais, com o uso de corantes oriundos da natureza, podem contribuir para a preservação do meio ambiente, geração de emprego e inclusão social.

Por fim, no contexto atual, há a necessidade de mais projetos desta natureza e de estudos futuros relacionados ao tema.

1 Status quo - expressão do latim que significa "o estado das coisas".

\section{Referências}

ARAÚJO, E. M. de. Corantes naturais para têxteis-da antiguidade aos tempos modernos. Conservar Património, n. ${ }^{\circ} 3$ e 4, p. 37 - 49, 2006 / 2007.

ARTESOL. As cores do cerrado e o tingimento Amaria. In: Artesol, 2020. (https://www.artesol.org.br/conteudos/visualizar/As-cores-do-cerrado-e-o-tingimento-Amaria).

ASTARA, O. H. Culture as the fouth pillar of sustainable development. Journal "Sustainable Development, Culture, Traditions", v. 2 a, p. 93-102, 2014.

BRATES, C. et al. Las evidencias de la industría Del Añil em La Cuenca Copan-Ch'orti'. In: SIMPOSIO DE INVESTIGACIONES ARQUEOLÓGICAS EN GUATEMALA, 18, 2004, Guatemala. Anais do XVIII Simposio de investigaciones arqueológicas en Guatemala, Guatemala: Asociación Tikal, 2005, p. 1-18. 
CASSELMAN, K. D. Praxis and Paradox: the culture of natural dyes in Britain, 1750-1900. Textile, v. 7, n. $\stackrel{9}{1}$, p. 6 - 27, 2009.

CHAN-BACAB, M. J et al. Characterization and dyeing potential of colorant-bearing plants of the Mayan área in Yucatan Peninsula, Mexico. Journal of Cleaner Production, v. 91, p.191200, mar 2015.

CONVENTION FOR THE SAFEGUARDING OF INTANGIBLE CULTURAL HERITAGE, 32, 2003, Paris. Convention for the Safeguarding of Intangible Cultural Heritage. Paris: UNESCO, 2003.

CUNNINGHAM, A. B. et al. Hanging by a thread: natural metallic mordant processes in traditional indonesian textiles. Economic Botany, v. 65, n. ำ 3, p.241-259, mai 2011.

DITTY, S. It's time for fashion revolution. White Paper, p.1-29, dez 2015.

FORSTER; S. V.; CHRISTIE, R. M. The significance of the introduction of synthetic dyes in the mid 19th century on the democratisation of western fashion. Journal of the International Colour Association, Leeds, v. 11, p. 1 -17, 2013.

GOMES, A. V. S.; COSTA, N. R. V.; MOHALLEM, N. D. S. Os tecidos e a nanotecnologia. Química Nova na Escola, v. 38, n. ำ 4, p.288-296, nov 2016.

GUIROLA, C. Natural dyes used in Mesoamerica since prehispanic age. Guatemala: Asociacion FLAAR Mesoamericana, 2010.

HANDAYANI, W.; KRISTIJANTO, A. I.; HUNGA, A. I. R. A water footprint case study in Jarum village, Klaten, Indonesia: the production of natural-colored batik. Environment, Development and Sustainability, p.1-14, fev 2018.

ISENMANN, A. F. Corantes. Timóteo: 2014.

JANSEN, S. et al. Aluminum hyperaccumulation in angiosperms: a review of Its phylogenetic significance. The Botanical Review, v. 68, n. ำ 2, p.235-269, abr 2002.

KADOLPH, S. Natural dyes: a traditional craft experiencing new attention. Delta Kappa Gamma Bulletin, p.14-17, fall 2008.

KANT, R. Textile dyeing industry an environmental hazard. Natural Science, Chandigarh, v.4, n. $\stackrel{\circ}{1}$, p.22-26, jan 2012.

MAGNUSDOTTIR, A. How fashion manufacturing will change after the Coronavirus. In: Forbes, 2020. (https://www.forbes.com/sites/aslaugmagnusdottir/2020/05/13/fashions-next-normal/\#7c2152a278f3)

NURSE, K. Culture as The Fourth Pillar of Sustainable Development. Commonwealth Secretariat, v. 11, p. 28-40, abr 2007

PEZZOLO, D. B. Tecidos: histórias, tramas, tipos e usos. 4. ed. São Paulo: Editora Senac São Paulo, 2013.

ROCHA, A. A. Amaria, design e cooperação. São Paulo: Auana, 2018.

RODRIGUES, J.; ARAÚJO, M. de C. Corantes naturais amazônicos: um estudo para a aplicação em produtos têxteis de moda. Diálogos e Ciência, n. ํ 34, p. 65-71, 2013.

RODRIGUES, J. A. R. Uso de corantes de origem natural para o tingimento de artigos têxteis de moda. 2013. 130 f. Dissertação (Mestrado em Têxtil e Moda) - Escola de Artes, Ciências e Humanidades, Universidade de São Paulo, São Paulo, 2013.

SCHULTE, N. K. et al. A moda no contexto da sustentabilidade. Modapalavra E-periódico, v. 6, n. ${ }^{\circ} 12$, p.194-211, jul/dez 2013.

SHAHID, M.; ISLAM, S.; MOHAMMAD, F. Recent advancements in natural dye applications: a review. Journal of Cleaner Production, v. 53, p.310-331, ago 2013. 
TERINTE, N. et al. Environmental assessment of coloured fabrics and opportunities for value creation: spin-dyeing versus conventional dyeing of modal fabrics. Journal of Cleaner Production, v.72, p.127 - 138, fev 2014.

TRANSFORMING OUR WORLD: THE 2030 AGENDA FOR SUSTAINABLE DEVELOPMENT, 2015, New York. Resolution adopted by the General Assembly on 25 September 2015. New York: United Nations, 2015. In: United Nations, 2015. (https://www.un.org/ga/search/view_doc. asp?symbol=A/RES/70/1\&Lang=E)

UNITED NATIONS CONFERENCE ON ENVIRONMENT \& DEVELOPMENT,1992, Rio de Janeiro. Agenda 21. Rio de Janeiro: United Nations Sustainable Development, 1992. In: United Nations Sustainable Development, 1992. (https://sustainabledevelopment.un.org/content/ documents/Agenda21.pdf)

UNITED NATIONS CONFERENCE ON SUSTAINABLE DEVELOPMENT RIO+20, 2012, Rio de Janeiro. Resolution adopted by the General Assembly on 27 July 2012. Rio de Janeiro: United Nations, 2012. In: United Nations, 2012. (https://www.un.org/ga/search/view_doc.asp?symbol=A/RES/66/288\&Lang=E)

UNITED NATIONS CONFERENCE ON THE HUMAN ENVIRONMENT, 1972, Stockholm. Report of the United Nations Conference on the Human Environment. Switzerland: United Nations, 1973. In: United Nations, 1972. (https://unesdoc.unesco.org/ark:/48223/pf0000004437)

SARAVANAN, D.; NITHYAPRAKASH, V. Fashion trends and their impact on the society. In: Conference on textile, Apparels and Fashion, Coimbatore, 2015. In: ResearchGate, 2015. (https://www.researchgate.net/publication/282571020_Fashion_trends_and_their_impact_ on_the_society)

VIANA, T. C. et al. O design de moda como ferramenta na utilização de pigmentos naturais na indústria têxtil. In: SIMPÓSIO DE DESIGN SUSTENTÁVEL, 5., 2015, Rio de Janeiro. Anais do $5^{\circ}$ Simpósio Brasileiro de design Sustentável. São Paulo: Blucher, 2016, p. 401- 410.

ZANONI, M. V. B.; YAMANAKA, H. Corantes: caracterização química, toxicológica, métodos de detecção e tratamento. São Paulo: Cultura Acadêmica, 2016. 